\title{
Building Envelope Prefabricated with 3D Printing Technology
}

\author{
Stelladriana Volpe ${ }^{1}\left(\mathbb{D}\right.$, Valentino Sangiorgio ${ }^{1,2,3}{ }^{\circledR}$, Andrea Petrella ${ }^{1}$, Armando Coppola ${ }^{4}$, Michele Notarnicola ${ }^{1}$ \\ and Francesco Fiorito $1, *$ (i)
}

1 DICATECH, Dipartimento di Ingegneria Civile, Ambientale, del Territorio, Edile e di Chimica, Politecnico di Bari, 70126 Bari, Italy; stelladriana.volpe@hotmail.it (S.V.); valentino.sangiorgio@poliba.it (V.S.); andrea.petrella@poliba.it (A.P.); michele.notarnicola@poliba.it (M.N.)

2 ICITECH, Instituto de Ciencia y Tecnología del Hormigón, Universitat Politècnica de València, 46022 València, Spain

3 FEUP, Faculdade de Engenharia da Universidade do Porto, 4200-465 Porto, Portugal

4 Easy House System s.r.l.s, 70125 Bari, Italy; coppolaingarch@gmail.com

* Correspondence: francesco.fiorito@poliba.it; Tel.: +39-080-5963-401

check for updates

Citation: Volpe, S.; Sangiorgio, V.; Petrella, A.; Coppola, A.; Notarnicola, M.; Fiorito, F. Building Envelope Prefabricated with 3D Printing Technology. Sustainability 2021, 13, 8923. https://doi.org/10.3390/ su13168923

Academic Editor: Aris Tsangrassoulis

Received: 21 July 2021

Accepted: 3 August 2021

Published: 9 August 2021

Publisher's Note: MDPI stays neutral with regard to jurisdictional claims in published maps and institutional affiliations.

Copyright: (c) 2021 by the authors. Licensee MDPI, Basel, Switzerland. This article is an open access article distributed under the terms and conditions of the Creative Commons Attribution (CC BY) license (https:/ / creativecommons.org/licenses/by/ $4.0 /)$.

\begin{abstract}
The Fourth Industrial Revolution represents the beginning of a profound change for the building sector. In the last decade, the perspective of shapes, materials, and construction techniques is evolving fast due to the additive manufacturing technology. On the other hand, even if the technology is growing fast and several 3D printed buildings are being developed worldwide, the potential of concrete 3D printing in building prefabrication remains unexplored. Consequently, the application of new digital fabrication technologies in the construction industry requires a redesign of the construction process and its components. This paper proposes a novel conception, design, and prototyping of a precast building envelope to be prefabricated with extrusion-based 3D concrete printing (3DCP). The new design and conception aim to fully exploit the potential of 3D printing for prefabricated components, especially in terms of dry assembly, speed of implementation, reusability, recyclability, modularity, versatility, adaptability, and sustainability. Beyond the novel conceptual design of precast elements, the research investigated the 3D printable cementitious material based on a magnesium potassium phosphate cement (MKPC), which was devised and tested to ensure good performances of the proposed component. Finally, a prototype has been realised in scale with additive manufacturing technology in order to verify the printability and to optimize the extruder path. This study leads us to believe that the combined use of prefabricated systems, construction automation, and innovative materials can decisively improve the construction industry's sustainability in the future.
\end{abstract}

Keywords: 3D concrete printing; prefabricated components; magnesium potassium phosphate cement; building envelopes; high-performance

\section{Introduction}

The first robotics and automated systems for construction were developed in the 1960s. However, since then, the technological progress in the construction industry has been very slow. Meanwhile, many other industrial sectors increased productivity and simultaneously increased efficiency. Therefore, the application of robotics and automated systems to the construction industry has the potential to reduce costs, improving both productivity and quality [1].

On the other hand, conventional construction techniques have reached maximum technological performance. Consequently, in the scientific and technical world, the current objective aims to revolutionise the construction sectors' techniques through the support of the digital fabrication $[2,3]$.

Digital fabrication is a production process that begins with digital drawings. It can be intended as an application of new technologies to embody the shapes and maximise the performance of materials, rather than imposing them in the production [4]. 
Among the digital fabrication techniques, extrusion-based 3D concrete printing (3DCP) is one of the most promising technologies for the renovation of the construction sector [5]. Indeed, different 3DCP applications for building construction have been developed in the last few years to modernise the construction sector [6]. Different studies have demonstrated that, compared with conventional construction processes, 3D printing can reduce costs, reduce the use of energy and waste material, eliminate dangerous jobs, and minimise the chance of errors, all while increasing sustainability and architectural freedom [6].

Since technology, performance, and freedom in printable forms are closely related to the study of materials, many types of extrudable cementitious materials have been developed in the last few years. The material used for concrete 3D printing must have specific properties including extrudability, viscosity, and workability [7-9]. Moreover, binding time and early robustness are essential to building a layer on another without losing the designed shape. At the same time, high structuration rates could lead to so-called cold joints and weak interfaces between layers. To provide some examples, in the material research field, high performance fibre reinforced with fine-aggregate concrete has been applied in Concrete Printing technology [6], and Ultra-High-Performance Concrete has been developed for large-scale 3DCP technology [10]. In addition, other studies have investigated Sorel cement in D-Shape technology [11]. Findings identified that geopolymerbased material [12] and granular material mixed with pulverized metal oxide $(\mathrm{MgO})$ reacted with magnesium chloride $\left(\mathrm{MgCl}_{2}\right)$ to produce an artificial double magnesium-carbonate sand stone [13].

Operatively, many 3D printed constructions made with different concrete mixtures and shapes can be found in the available literature [11,14-16]. Despite the fact that 3D printing of concrete buildings is growing fast, and whole 3D printed houses are now widespread in the world, there is still limited application and experimentation of 3D printing for concrete components prefabrication. However, prefabrication through 3D printing has enormous potential, especially in a long-term vision where the combination with robotic construction processes can lead to a fully automated and sustainable building process. Indeed, recent researchers have demonstrated the interest of the construction sector in the combination between digital concrete and prefabrication. For example, Meibodi et al. applied the Smart Dynamic Casting (SDC) to prefabricate and optimise load-bearing concrete structures, and to create the Smart Slab by using a large 3D printed formwork [17]. Another example of precast digital concrete is the Eggshell fabrication process [18]. Moreover, one of the few applications of 3D printing directly used for precast components in regard to the project "Office of the Future" of Killa Design, where office boxes are realised by using a large size prefabrication $(8.9 \times 1.9 \times 2.1 \mathrm{~m})$ [19]. The $3 \mathrm{DCP}$ was also applied to slab prototypes in both the lightweight concrete ceiling designed at TU Graz [20] and the prefabricated concrete slabs built at ETH Zürich [21,22]. Another possible advantage of 3DCP is the concrete optimisation through efficient shapes, placing material only where functionally required. This controlled environment of concrete can be maximised by prefabrication, which can allow for the calibration of machines and the achievement of geometric complexity using 3DCP. In this regard, Anton et al. developed a 3DCP setup for the automated prefabrication of bespoke columns [23].

On the other hand, the previous experiences of 3D printing for prefabrication focused on special components or uncommon constructions. Indeed, the limitations of previous studies concern the design of the precast component, which are not realised for the needs and performances of common buildings. In addition, the large size of the previous experiences compromises the easy assembly in situ (e.g., operation's speed execution, specific machines for handling, and workers safety). Consequently, the combination between 3D printing and prefabrication for the building construction sector is still open with multiple aspects to explore.

In this study, we propose the design and prototyping of a new prefabricated system for innovative building envelopes made with $3 \mathrm{D}$ printing. The new design and conception aim to fully exploit the potential of $3 \mathrm{D}$ printing for prefabricated components, including 
the dry assembly, speed of implementation, reusability, recyclability, modularity, versatility, adaptability, and sustainability. In particular, the envelope system is composed of precast elements that can be printed on-site and assembled entirely dry to maximise the reversibility. Moreover, they can be easily dismantled, reused, or recycled. The dry assembly allows for more simplicity of commissioning and speed of assembly. The elements have modular dimensions and high levels of mobility, but the 3D printing technology makes it possible to simply change the dimensions of the blocks, specifically the height and width, and to adapt the proportions to every situation. The versatility of use does not only concern the solving of geometric problems, but also the possibility of applying the system to different types of indoor environments. Therefore, we tried to achieve an innovative aesthetic impact that is close to the traditional masonry in appearance, but that also emphasises the characteristics of the innovative technology. Another important aspect regards the structural and energy performance included in the proposed prototype. In order to ensure good performances, an innovative magnesium potassium phosphate cement (MKPC) has been specifically designed (and tested in previous research [24]) to improve the performance of the proposed prefabricated system.

To sum up, the novelties of the proposed prefabricated system are threefold:

- The combination between 3D printing and prefabrication for the building construction sector is explored in depth by designing a new "printable" prefabricated system.

- The proposed multi-objective design combines, for the first time, different important aspects in a precast 3D printed component, including the following functions: thermal insulation, structural reinforcement, and housing of the technological plant.

- A sustainable magnesium potassium phosphate cement (MKPC) is developed for the proposed 3D printed prefabricated system in order to avoid shell collapses during the printing process and to ensure good structural and energy performances.

\section{Project Design: The Innovative Building Envelope Designed for 3D Printing}

\subsection{Concept: The Multi Objective Design}

An innovative 3D printed building envelope construction was designed. To this aim, different modular elements have been conceived (Figure 1) to perform different functions, like thermal insulation, structural reinforcement, and building services integration. The elements can be printed industrially or on site, and can be assembled with a spigot and socket joint.

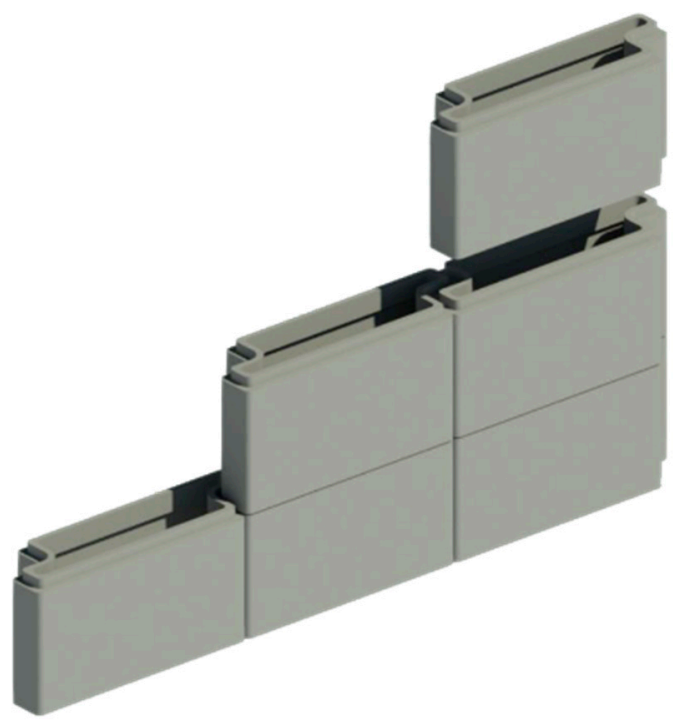

Figure 1. Innovative building envelope designed for 3D printing.

The concept is based on functional segmentation, as shown in Figure 2. Starting from a block of rectangular shape, a translational movement along the symmetry axis creates 
a half lap joint. This configuration prevents the discontinuity of thermal insulation, thus reducing the risk of thermal bridges. In addition, an insulating material panel can be inserted on one side of every single block.

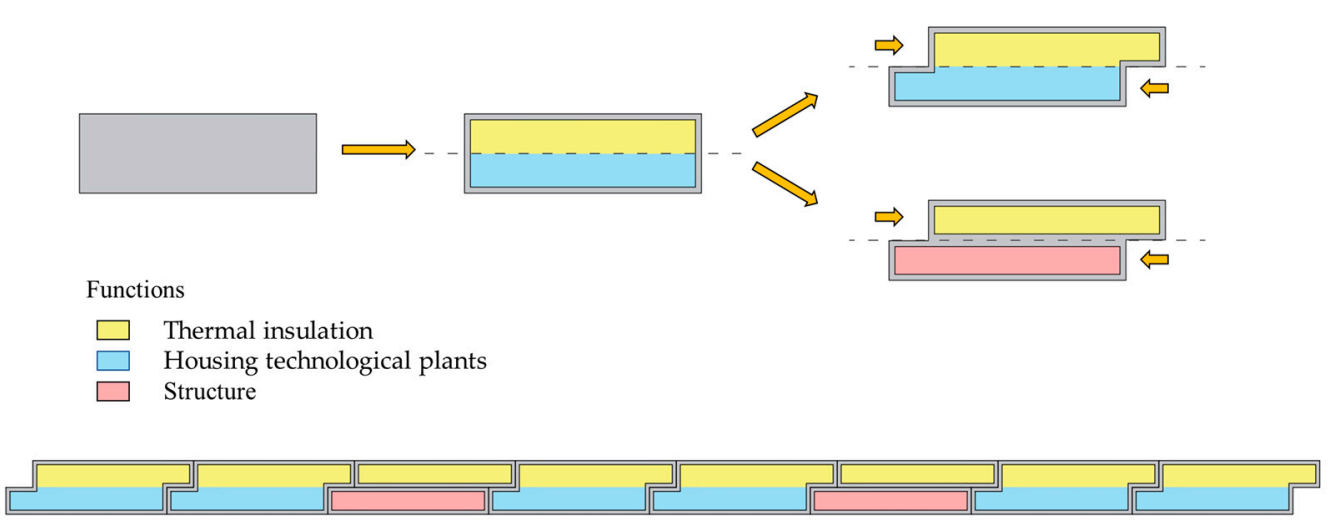

Figure 2. Zones with different functions in a storage element.

In this process, two types of basic elements are designed: (i) one with thermal insulation and an air cavity for building services integration (standard blocks), and (ii) one with thermal and structural functions (structural blocks). These are obtained by including an internal partition to separate the structural reinforcement zone and to create a suitable formwork (Figure 2).

\subsection{Precast Elements: Dry Assembly, Modularity and Adaptability}

The two types of basic elements have the same shape and size to ensure a modularity of both structural and non-structural components (Figure 3). The visible side is $120 \mathrm{~cm}$ in length (the total length is $140 \mathrm{~cm}$ ) and $60 \mathrm{~cm}$ in height. The total depth of the panel is $40 \mathrm{~cm}$.

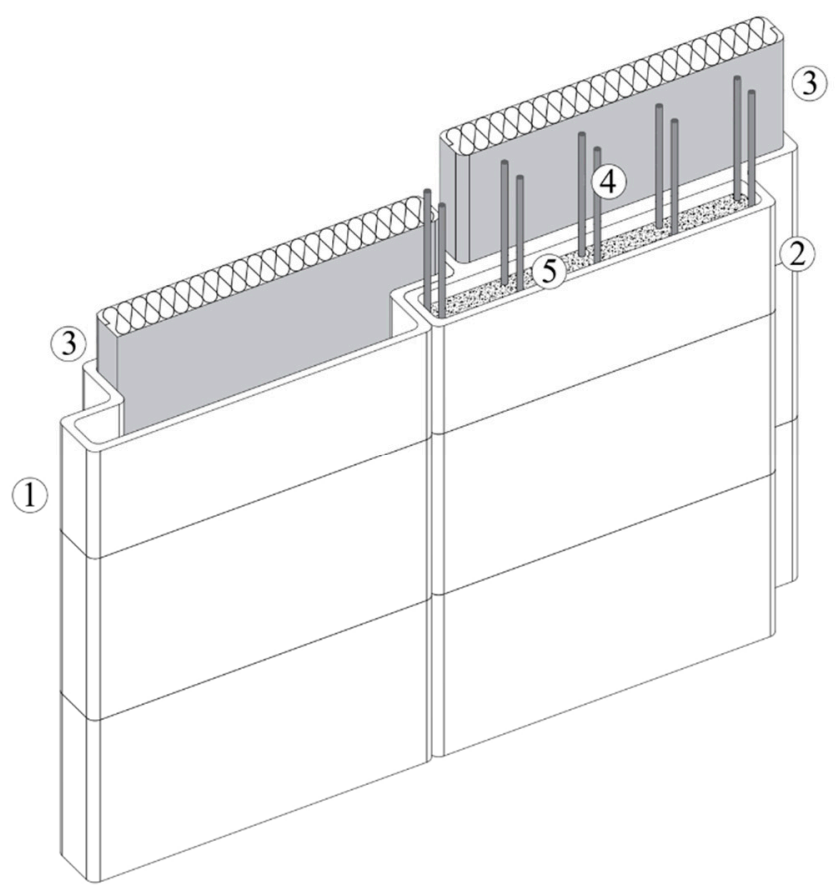
Legend
(1.) Standard block type
(2.) Structural block type
(3.) Insulating material panel
(4.) Rebars
(5.) Concrete cast

Figure 3. The two types of basic elements.

The thermal insulation panel can simply be placed inside the block after the 3D printing process is completed. Therefore, the blocks are ready to be assembled when they are moved to the construction site. 
The structural blocks have two parts that are physically separated. At the time of building, one side has the panel already included, and the other side is empty. The elements are installed on the reinforcement and used for casting the concrete as formwork.

To fix the edge of the wall, the block happens to resemble a T-shape. This way, the special edge block ensures the continuity of the insulation with the perpendicular element.

Figure 4 shows a technical representation of the blocks. The adoption of a special edge block con be noticed in Figure $4 \mathrm{a}$, while Figure $4 \mathrm{~b}$ shows the details of the connection between the block and a common reinforced concrete floor slab.

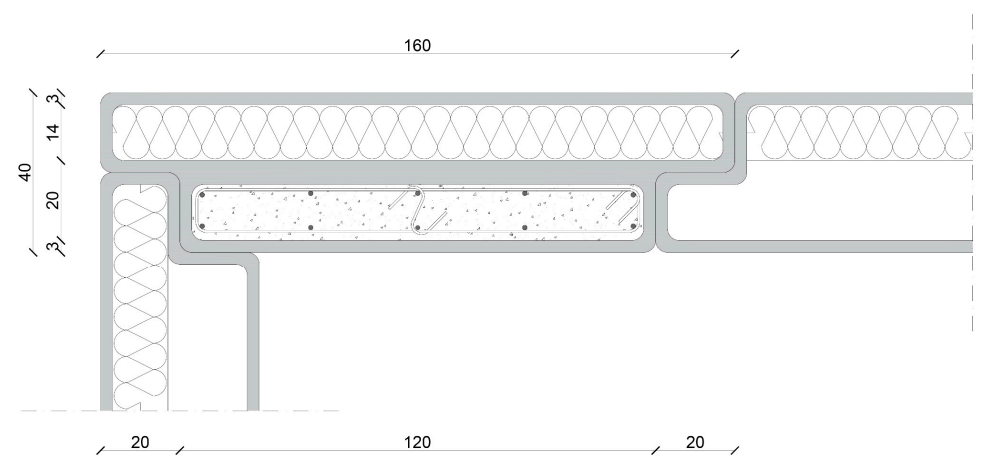

(a)

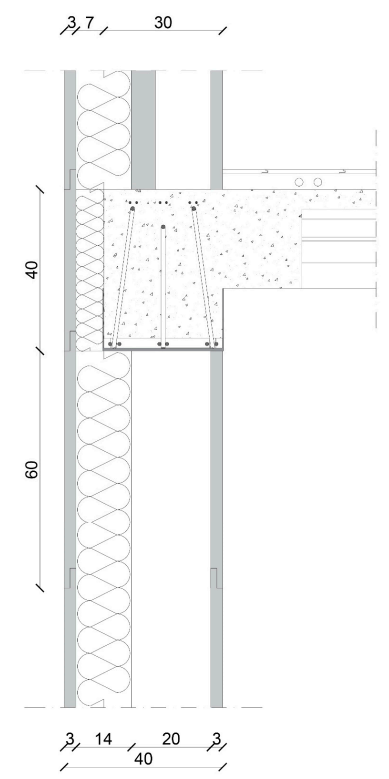

(b)

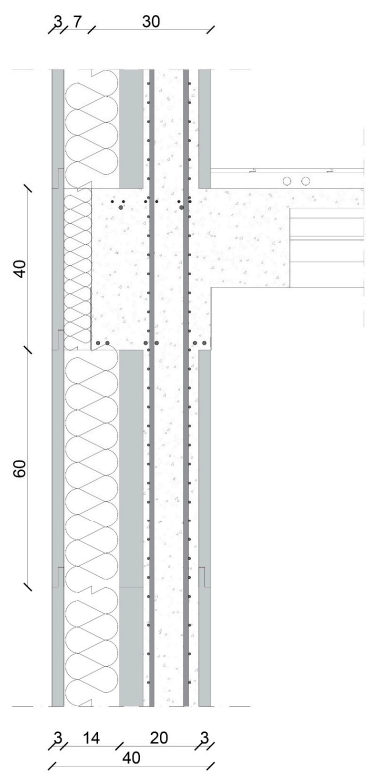

(c)

Figure 4. Building envelope section detail: (a) horizontal section of the envelope system at the edge; (b) vertical section of the beam-wall; (c) vertical section at the beam-column node.

The proposed sizes are modular, although the 3D printing technology allows for a simple modification of the height of each block in order to reduce or increase the number of layers, or to customise the construction.

\subsection{Material: Printability and Sustainability}

As the concrete rheological requirements influence the input parameters of 3D printing, specific studies were performed. According to previous studies [8], the printing test of suitable materials should search for the following properties: (i) layer thickness $h_{0}$, (ii) maximum height $H$, (iii) layer width, and (iv) radius curvature. Moreover, according to Bos et al. [8]:

- $\quad$ the initial yield stress must be greater than $g \cdot h_{0}$ where $g$ is the gravitational acceleration.

- Yield stress in the bottom layer must be greater than $g \cdot \rho \cdot H / \sqrt{ } 3$ where $\rho$ is the material density.

- Initial shear elastic modulus must be higher than $g \cdot h_{0} / \varepsilon_{t o l}$ where $\varepsilon_{t o l}$ is the tolerable deformation of the layer.

- Young elastic modulus must be higher than $3 \cdot g \cdot H^{3} / 2^{2}$.

In the proposed research, we identified a printable material (studied in detail in a previous study [24]) that can be suitable to guarantee good performances for the designed component. We proposed an innovative MKPC cementitious material that could reach the appropriate characteristics of plasticity, fluidity, workability, and setting time needed for 3D printing [25,26]. Two different compositions of the MKPC were obtained; one with common sand aggregates, and an alternative with recycled expanded glass that can be 
more performant in terms of thermal transmittance and sustainability [24]. Table 1 shows the two mix compositions of the MKPC, while Table 2 shows their mechanical properties.

Table 1. Mix composition.

\begin{tabular}{cccccccc}
\hline Compositions & MgO & KDP & FA & Borax & SF & Water & Aggregates \\
\hline 1st with sand & $5 \%$ & $6 \%$ & $8 \%$ & $52 \%$ & $2 \%$ & $19 \%$ & $8 \%$ \\
\hline 2nd with glass & $5 \%$ & $5 \%$ & $8 \%$ & $51 \%$ & $2 \%$ & $21 \%$ & $8 \%$ \\
\hline MgO (Magnesium oxide); KDP (Potassium dihydrogen phosphate); FA (Fly ash); SF (Silica fume).
\end{tabular}

Table 2. MKPC mechanical properties.

\begin{tabular}{ccccccc}
\hline \multirow{2}{*}{ Compositions } & \multirow{2}{*}{ Density } & \multirow{2}{*}{ Flow } & \multicolumn{2}{c}{ Flexural Strength [MPa] } & \multicolumn{2}{c}{ Compressive Strength [MPa] } \\
\cline { 3 - 7 } & & & $\mathbf{9 0}$ min & 7 days & 90 min & 7 days \\
\hline 1st with sand & $1350 \mathrm{~kg} / \mathrm{m}^{3}$ & $46 \%$ & $1.23 \pm 0.06$ & $1.71 \pm 0.09$ & $3.14 \pm 0.16$ & $5.73 \pm 0.29$ \\
2nd with glass & $950 \mathrm{~kg} / \mathrm{m}^{3}$ & $23 \%$ & $0.94 \pm 0.05$ & $1.63 \pm 0.08$ & $1.99 \pm 0.10$ & $4.80 \pm 0.24$ \\
\hline
\end{tabular}

\subsection{Structural and Energy Performances}

This section presents some preliminary investigations regarding the structural and energy performance of the proposed precast blocks. In particular, beyond the traditional structural performances necessary for the construction operation, a 3D printed block needs to have good characteristics to ensure a correct printability. The resistance of the lower layers must be able to quickly support the weight of subsequent layers during the extrusion process. Assuming a layer width of $3 \mathrm{~cm}$, the section area of the printed elements is $0.1 \mathrm{~m}^{2}$ and the volume is $0.06 \mathrm{~m}^{3}$. The supposed specific weight using MKPC cement with sand is $1350 \mathrm{~kg} / \mathrm{m}^{3}$, while the supposed specific weight using MKPC cement with expanded glass as aggregates is $950 \mathrm{~kg} / \mathrm{m}^{3}$. Consequently, the weight of a single block would be $81 \mathrm{~kg}$ or $57 \mathrm{~kg}$, respectively.

According to the structural tests previously performed [24] (Table 2), the compressive strength (at 90 min curing) can vary between 3.14 MPa and $1.99 \mathrm{MPa}$ depending on the used admixture of MKPC. This compressive strength is wide enough to enable printing without losing the designed shape. In addition, the compressive strength after $90 \mathrm{~min}$ allows for direct assembly of the block on site, ensuring the support of other blocks for fast printing and implementation.

The energy performance of the vertical closing system depends on the stratigraphy. The insulating material panel can be of variable thickness up to $14 \mathrm{~cm}$, and can have variable insulating performance depending on the indoor requirements and the climatic conditions on site. We can value the global performances, assuming the use of a conventional insulation material like rock wool. Tables 3 and 4 show the values of thermal transmittance of the two types of blocks (the first with an empty air cavity, and the second with the air cavity filled with reinforced concrete). The values of thermal transmittances are compliant with the energy codes of most central and southern European countries [27-29].

Table 3. Thermal transmittance of the standard block type.

\begin{tabular}{|c|c|c|c|c|c|}
\hline & Stratigraphy & $\begin{array}{c}\text { Thickness } \\
\text { (m) }\end{array}$ & $\begin{array}{l}\text { Thermal } \\
\text { Conductivity } \\
(\mathrm{W} /(\mathrm{m} \cdot \mathrm{K}))\end{array}$ & $\begin{array}{c}\text { Thermal } \\
\text { Insulance } \\
\left(\left(\mathrm{m}^{2} \cdot \mathrm{K}\right) / \mathrm{W}\right)\end{array}$ & $\begin{array}{c}\text { Thermal } \\
\text { Transmittance } \\
\left(\mathrm{W} /\left(\mathrm{m}^{2} \cdot \mathrm{K}\right)\right)\end{array}$ \\
\hline & MKPC & 0.03 & 0.70 & 0.04 & \\
\hline & Rock wool & 0.14 & 0.04 & 3.68 & \\
\hline & Air & 0.20 & & & \\
\hline \multirow[t]{2}{*}{ 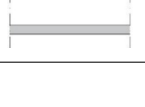 } & MKPC & 0.03 & 0.70 & 0.04 & \\
\hline & Envelope & & & 3.91 & 0.26 \\
\hline
\end{tabular}


Table 4. Thermal transmittance of the structural block type.

\begin{tabular}{|c|c|c|c|c|c|}
\hline & Stratigraphy & $\begin{array}{c}\text { Thickness } \\
\text { (m) }\end{array}$ & $\begin{array}{l}\text { Thermal } \\
\text { Conductivity } \\
(\mathrm{W} /(\mathrm{m} \cdot \mathrm{K}))\end{array}$ & $\begin{array}{l}\text { Thermal } \\
\text { Insulance } \\
\left(\left(\mathrm{m}^{2} \cdot \mathrm{K}\right) / \mathrm{W}\right)\end{array}$ & $\begin{array}{c}\text { Thermal } \\
\text { Transmittance } \\
\left(\mathrm{W} /\left(\mathrm{m}^{2} \cdot \mathrm{K}\right)\right)\end{array}$ \\
\hline \multirow{6}{*}{$2 \ldots$} & MKPC & 0.03 & 0.70 & 0.04 & \\
\hline & Rock wool & 0.14 & 0.04 & 3.68 & \\
\hline & MKPC & 0.06 & 0.7 & 0.04 & \\
\hline & Concrete & 0.14 & 1.80 & 0.08 & \\
\hline & MKPC & 0.03 & 0.70 & 0.04 & \\
\hline & Envelope & & & 4.07 & 0.25 \\
\hline
\end{tabular}

\subsection{On Site Assembly and Fast Implementation}

The proposed blocks are designed to guarantee an easy on-site assembly and a good speed of implementation. In particular, the construction of a reinforced concrete building by using the 3D printable blocks takes place floor by floor, and the construction of every wall can be described in five steps (Figure 5):

- The reinforcing bars are placed in the position where the structural blocks are to be assembled (Figure 5a);

- The structural blocks are stacked on rebars (Figure 5b) and then the walls are completed by placing the standard block;

- The blocks are fitted together by rotating the single element to the correct position and then placing it on the element below (Figure $5 \mathrm{c}$ ). In this step, blocks at the corner should be placed first to facilitate assembly;

- The concrete is cast in the formwork part of the structural block (Figure $5 \mathrm{~d}$ );

- After the setting time, the wall is complete (Figure $5 \mathrm{~d}$ ), and the next step concerns the realization of a beam over the wall.

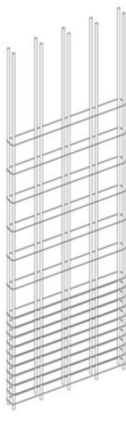

(a)

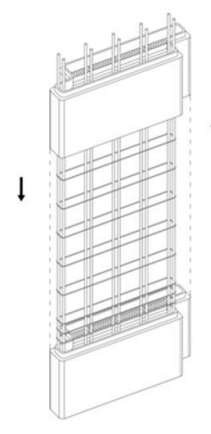

(b)

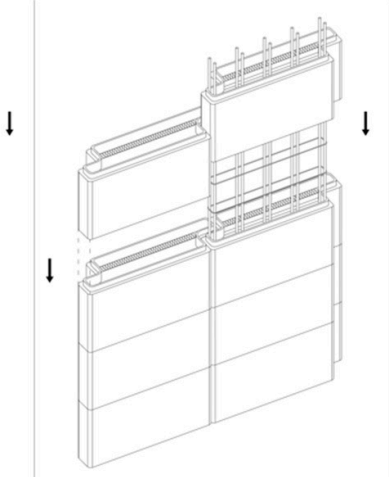

(c)

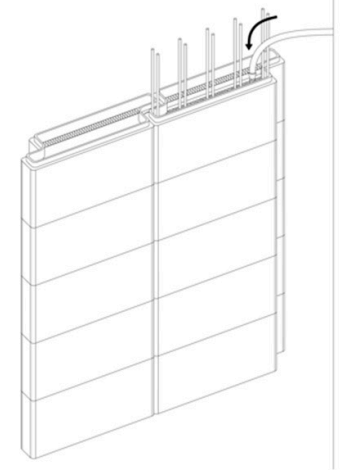

(d)

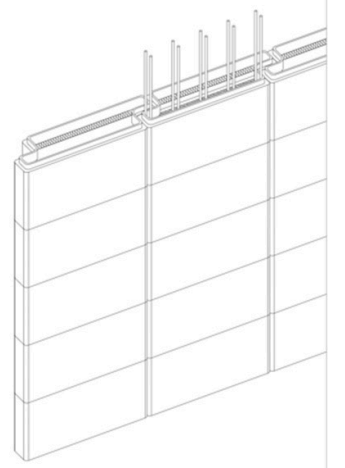

(e)

Figure 5. Building of the envelope system: (a) placing of reinforcing bars; (b) stacking of the elements on rebars; (c) placing of standard blocks on the element below; (d) casting of the pillars in the formwork part of the block; (e) completion of the wall.

The block system can be combined with a horizontal mixed steel-concrete structure. In correspondence with the slab, a space must be left to apply the thermal bridge correction by using an insulating panel. Then, the realisation of the next floor can be continued.

The developed system is designed to be visually close to a classic brick wall, even if the used material is cement. On the other hand, the proposed block uses a new concept, a new production technology, and an innovative construction technique. In this way, it is possible to take the first steps towards social acceptance of this technology for residential construction. 
Concerning the finishing, the proposed system does not require coatings, which minimises manual operations, simplifies assembly on site, and increases the degree of automatization (excluding the possibility of human error). To this aim, it is possible to leave visible the shape of the wall and the layer texture given by the use of the production method. This solution is certainly easier and more sustainable, but the construction sector is not entirely ready for an aesthetic impact so different from the common practice. Consequently, classic plastering or plasterboard panelling can be proposed for residential buildings or to meet specific aesthetic needs of some users. Unlike classic plastering, the proposed blocks are compatible with green walls (Figure 6) thanks to the proposed MKPC, which is specifically developed with low permeability and corrosive resistance against chemicals. This flexibility can meet the necessities of different stakeholders and varying intended uses.

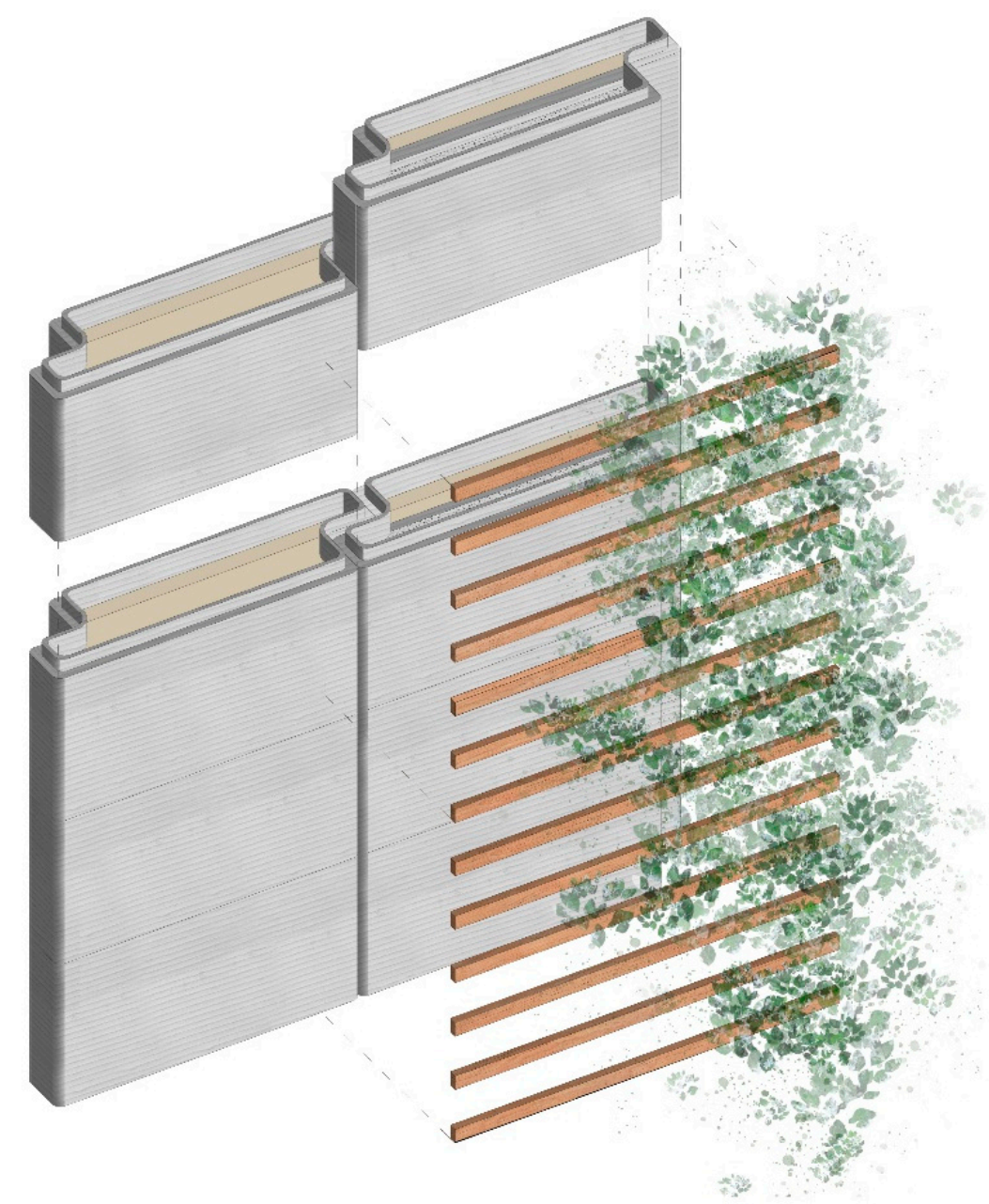

Figure 6. Example of combined system with green walls for functional and aesthetic purposes.

\section{Prototype}

\subsection{Printability and the Extruder Path}

An important characteristic of the proposed design concerns the printability and possible optimization of the extrusion path. Indeed, the adopted shape allows for a continuous extrusion, facilitation of the production process, and for a more uniform quality of products. In particular, the extruder path can be continuous for all types of blocks. Figure 7 shows how the proposed shape allows for a continuous extrusion process for the standard blocks without creating irregularities (in the left). In addition, the extrusion path of the structural blocks with the formwork designed for concrete casting can be created with a single overlapping of the extrusion path. 

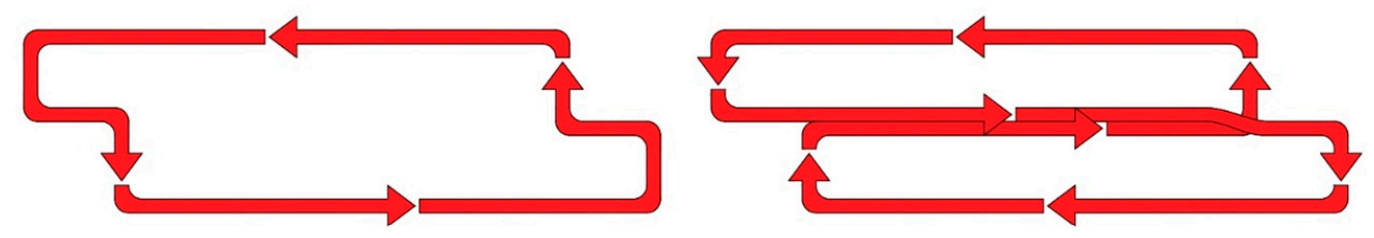

Figure 7. Extruder path of the different block types.

\subsection{The Prototype Result}

The proposed model has been prototyped in scale within a printing test. More specifically, the model was reproduced to a scale of 1:10 using a Delta Wasp 40100 in the laboratory "FabLab Poliba" of the Polytechnic of Bari. The 3D printed model has demonstrated the efficiency of the designed geometry and the effectiveness of the proposed extruder path (Figure 8). Indeed, the extrusion does not incur common printing errors, and the printed shape is achieved without deformation reflecting the 3D digital model [30].

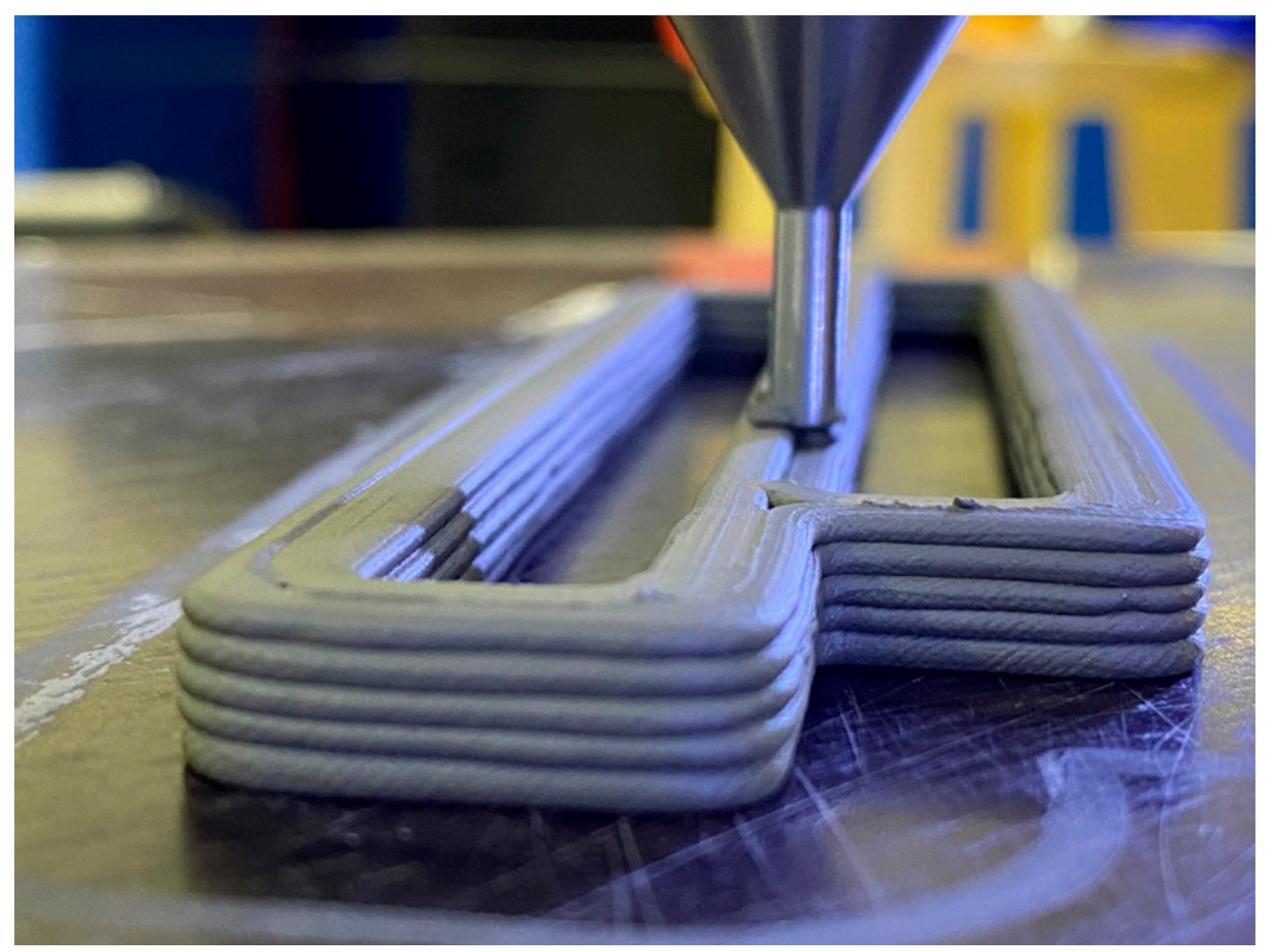

Figure 8. Extrusion process.

The prototype after the 3D printing was filled on one side with rock wool and on the other side with the reinforced concrete as proposed by the present study. The obtained prototype, including insulation material and reinforcement, is shown in Figure 9. 


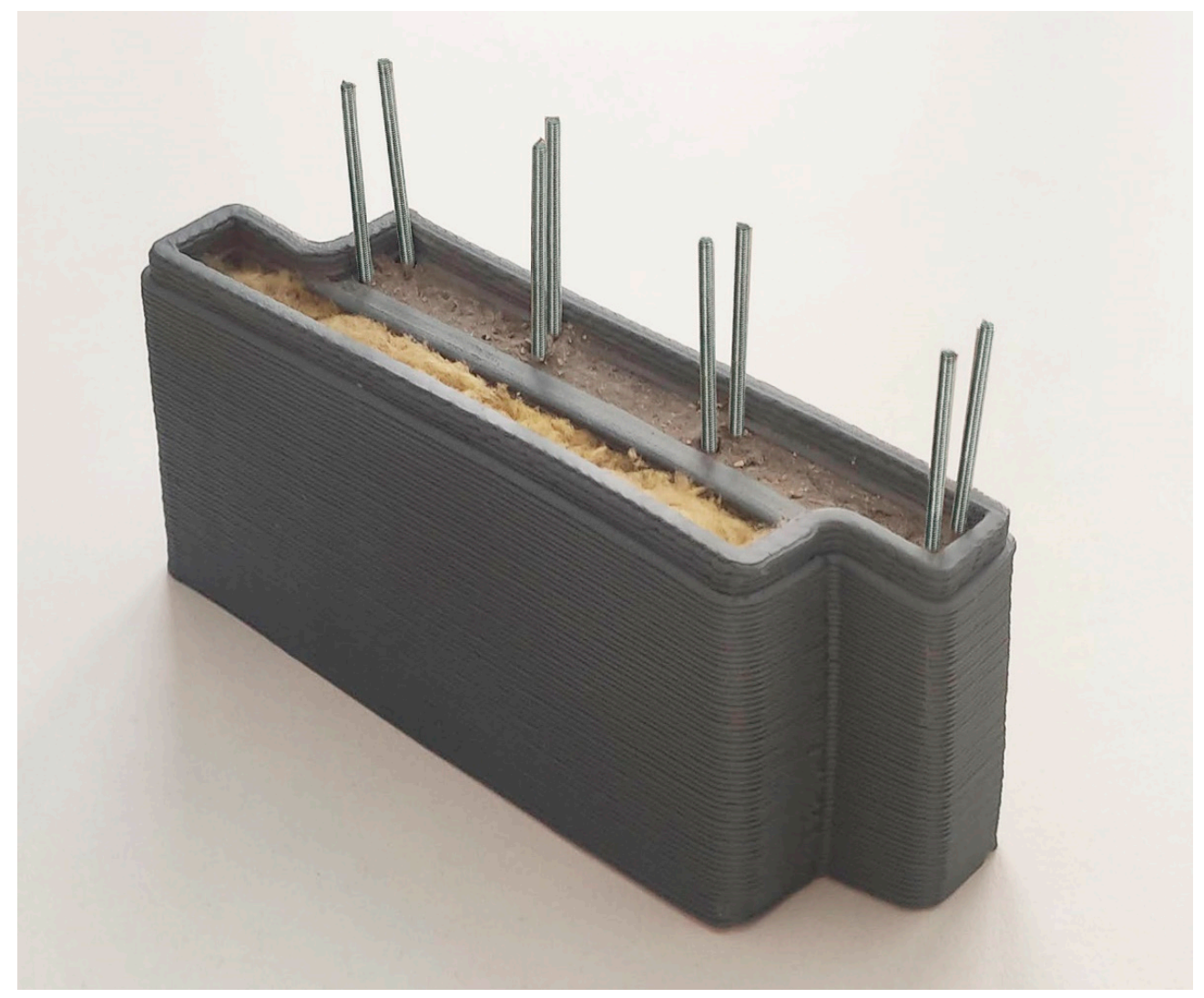

Figure 9. Picture of the printed Prototype in scale 1:10.

\section{Discussion and Comparison}

In recent years, few applications can be found in literature concerning the field of prefabricated 3D printed concrete [19]. On the other hand, many other techniques have been applied to 3D construction printing (e.g., 3DCP realised on site or large-scale 3DCP constructions). To this aim, this section discusses the characteristics of the proposed solution in comparison with other 3D construction printing techniques by emphasising the pros and cons of each. In the following discussion, the analysed aspects include: (i) different use of prefabrication; (ii) use of thermal performing printable material; (iii) integration of thermal insulation; and (iv) integration of reinforcement.

Concerning the prefabrication, the only comparable study is "Office of the Future" of Killa Design [19]. In this case, the structure was first realised in two 3D printed precast components that were shipped and installed on site. The limitation of this large prefabrication technique concerns the voluminous dimension of each U-shaped piece, which influences the transport and the assembly phases in situ, including the operation's speed execution, specific machines required for handling, and the safety of workers. On the contrary, the proposed system is composed of blocks of reduced dimensions that allow production with smaller printers, ultimately saving resources. In addition, the proposed blocks are designed to be used at a large scale by enhancing easy transport and on-site assembly.

The integration of effective thermal performances is an important aspect of this concept that has already been investigated in previous $3 \mathrm{D}$ construction printing applications. A possible solution is the production of thermal performing printable material with the inclusion of Aerogels [31], air bubbles [32], or lightweight aggregates [33] into cementitious composites to reduce its thermal conductivity. Analogously, the strategy of the integration of lightweight aggregates is pursued in the proposed blocks system using the MKCP composition with glass.

Furthermore, another possible technique to reach efficient thermal performance is to integrate the thermal insulation. In previous investigations, insulation material has been 
included in the wall system, as is the case in the study of Kaszynka et al. [34], which used mineral wool and polyurethane foam between the 3D printed wall layers. Moreover, other techniques included thermal material in the internal spaces of the printed element $[35,36]$, similarly to the proposed solution. Indeed, in the current research, the block is enterally prefabricated, placing the insulation panel immediately after the print in a specifically designed space (before the assembly in situ). In addition, the proposed dry assembly ensures the reuse and recycle of the insulation material at the end of its life cycle.

Finally, the construction reinforcement of the proposed blocks system can be compared to Contour Crafting technology developed at the University of Southern California [37]. This technology extrudes a vertical concrete formwork inserting custom-made reinforcement ties. In this solution, concrete is poured into the formwork in different steps to control the later pressure. Instead, the proposed precast formwork allows for casting of the concrete directly without waiting for the concrete to cure, with a consequent acceleration of the on-site assembly phase. On the other hand, the application of reinforcements in the 3D printed components (during extrusion) is still an open issue in the related literature. This drawback could be improved for the proposed block with the future evolution of technology.

\section{Conclusions}

This paper explores for the first time the potential of 3D printing technology in synergy with prefabrication to realise a novel building envelope suitable for different types of building constructions. In particular, the research demonstrates the potential of 3D printing combined with prefabrication through the design and prototyping of a new prefabricated system capable of ensuring dry assembly, speed of implementation, reusability, recyclability, modularity, versatility, adaptability, and sustainability.

In order to reach high performances, the shape is optimized to exploit the actual 3D printing technology and to achieve effective thermal insulation, structural reinforcement, and housing of the technological plant. In addition, a magnesium-potassium-phosphate cement has been specifically designed to ensure structural performance and sustainability together with printability. Finally, a prototype in scale 1:10 has been developed to verify the printability and correct extrusion path.

In comparison with previous research, this paper proposed the design of 3D printed precast components to be used on a large scale for common buildings. On the contrary, previous experiences focused on special components for uncommon constructions without considering the aspects of performance and sustainability involved in the large-scale application.

This research opens up new perspectives and possibilities to use 3D printing for the prefabrication of precast components for building construction. Future research will develop a real scale prototype to be applied in a pilot case study to take a further step towards the use and social acceptance of this innovative construction technique.

Author Contributions: Conceptualization, S.V., V.S. and F.F.; methodology, S.V., V.S., A.P., M.N. and F.F.; software, S.V. and V.S.; validation, S.V. and V.S.; formal analysis, S.V. and V.S.; investigation, S.V. and V.S.; data curation, S.V. and V.S.; writing-original draft preparation, S.V. and V.S.; writingreview and editing, A.P., A.C., M.N. and F.F.; visualization, S.V. and V.S.; supervision, A.P., A.C., M.N. and F.F. All authors have read and agreed to the published version of the manuscript.

Funding: This research received no external funding.

Institutional Review Board Statement: Not applicable.

Informed Consent Statement: Not applicable.

Data Availability Statement: Not applicable.

Acknowledgments: A special thanks is addressed to FabLab Bitonto for supporting the development of the prototype in the laboratory "Fablab Poliba".

Conflicts of Interest: The authors declare no conflict of interest. 


\section{References}

1. Delgado, J.M.D.; Oyedele, L.; Ajayi, A.; Akanbi, L.; Akinade, O.; Bilal, M.; Owolabi, H. Robotics and automated systems in construction: Understanding industry-specific challenges for adoption. J. Build. Eng. 2019, 26, 100868. [CrossRef]

2. Bock, T. Construction Robotics enabling Innovative Disruption and Social Supportability. In Proceedings of the 32nd International Symposium on Automation and Robotics in Construction (ISARC), Oulu, Finland, 15-18 June 2015; Volume 32, pp. 1-11.

3. Wangler, T.P.; Roussel, N.; Bos, F.P.; Salet, T.A.M.; Flatt, R.J. Digital Concrete: A Review. Cem. Concr. Res. 2019, 123, 105780. [CrossRef]

4. Picon, A.; Ahrens, C.; Sprecher, A. Digital Fabrication, Between Disruption and Nostalgia. In Instabilities and Potentialities, 1st ed.; Routledge: New York, NY, USA, 2019; pp. 223-238.

5. Buswell, R.A.; Leal da Silva, W.R.; Bos, F.P.; Schipper, H.R.; Lowke, D.; Hack, N.; Kloft, H.; Mechtcherine, V.; Wangler, T.; Rousseli, N. A process classification framework for defining and describing Digital Fabrication with Concrete. Cem. Concr. Res. 2020, 134, 106068. [CrossRef]

6. Nematollahi, B.; Xia, M.; Sanjayan, J. Current Progress of 3D Concrete Printing Technologies. In Proceedings of the International Symposium on Automation and Robotics in Construction, Taipei, Taiwan, 28 June-1 July 2017; IAARC Publications: Taipei, Taiwan, 2017.

7. Pacewicz, K.; Sobotka, A.; Gołek, Ł. Characteristic of materials for the 3D printed building constructions by additive printing. MATEC Web Conf. 2018, 222, 01013. [CrossRef]

8. Roussel, N. Rheological requirements for printable concretes. Cem. Concr. Res. 2018, 112, 76-85. [CrossRef]

9. Bos, F.; Wolfs, R.; Ahmed, Z.; Salet, T. Additive manufacturing of concrete in construction: Potentials and challenges of 3D concrete printing. Virtual Phys. Prototyp. 2016, 11, 209-225. [CrossRef]

10. Gosselin, C.; Duballet, R.; Roux, P.; Gaudillière, N.; Dirrenberger, J.; Morel, P. Large-scale 3D printing of ultra-high performance concrete-A new processing route for architects and builders. Mater. Des. 2016, 100, 102-109. [CrossRef]

11. d-shape. Available online: https://d-shape.com (accessed on 21 July 2021).

12. Xia, M.; Sanjayan, J.G. Method of formulating geopolymer for 3D printing for construction application. Mater. Des. 2016, 110, 382-390. [CrossRef]

13. Lowke, D.; Dini, E.; Perrot, A.; Weger, D.; Gehlen, C.; Dillenburger, B. Particle-bed 3D printing in concrete constructionPossibilities and challenges. Cem. Concr. Res. 2018, 112, 50-65. [CrossRef]

14. apis cor. Available online: https:/ / www.apis-cor.com/ (accessed on 12 July 2021).

15. Icon. Available online: https:/ / www.iconbuild.com/ (accessed on 1 July 2021).

16. Sakin, M.; Kiroglu, Y.C. 3D Printing of Buildings: Construction of the Sustainable Houses of the Future by BIM. Energy Procedia 2017, 134, 702-711. [CrossRef]

17. Aghaei Meibodi, M.; Jipa, A.; Giesecke, R.; Shammas, D.; Bernhard, M.; Leschok, M.; Dillenburger, B. Smart Slab: Computational Design and Digital Fabrication of a Lightweight Concrete Slab. In ACADIA 2018 Recalibration: On Imprecision and Infidelity, Proceedings of the 38th Annual Conference of the Association for Computer Aided Design in Architecture; Acadia Publishing Company: 55 Cottage St, Bar Harbor, Mexico, 2018; pp. 434-443.

18. Burger, J.; Lloret-Fritschi, E.; Scotto, F.; Demoulin, T.; Gebhard, L.; Mata-Falco, J.; Gramazio, F.; Kohler, M.; Flatt, R.J. Eggshell: Ultra-Thin Three-Dimensional Printed Formwork for Concrete Structures. 3D Print. Addit. Manuf. 2020, 7, 48-59. [CrossRef]

19. Dubai Future Foundation. Available online: https:/ / www.dubaifuture.gov.ae/ (accessed on 22 June 2021).

20. Hansemann, G.; Schmid, R.; Holzinger, C.; Tapley, J.P.; Kim, H.H.; Sliskovic, V.; Freytag, B.; Trummer, A.; Peters, S. Additive fabrication of concrete elements by robots: Lightweight concrete ceiling. In Fabricate 2020: Making Resilient Architecture; UCL Press: London, UK, 2020; pp. 124-129.

21. Anton, A.; Jipa, A.; Reiter, L.; Dillenburger, B. Fast Complexity: Additive Manufacturing for Prefabricated Concrete Slabs. In Second RILEM International Conference on Concrete and Digital Fabrication; RILEM Bookseries; Springer: Cham, Switzerland, 2020; pp. 1067-1077.

22. Jipa, A.; Meibodi, M.A.; Giesecke, R.; Shammas, D.; Leschok, M.; Bernhard, M.; Dillenburger, B. 3D-Printed Formwork for Prefabricated Concrete Slabs. In Proceedings of the 1st International Conference on 3D Construction Printing (3DcP), Hawthorn, Australia, 26-28 November 2018.

23. Anton, A.; Reiter, L.; Wangler, T.; Frangez, V.; Flatt, R.J.; Dillenburger, B. A 3D concrete printing prefabrication platform for bespoke columns. Autom. Constr. 2021, 122, 103467. [CrossRef]

24. Volpe, S.; Petrella, A.; Sangiorgio, V.; Notarnicola, M.; Fiorito, F. Preparation and characterization of novel sustainable composites based on magnesium potassium phosphate cement for additive manufacturing. submitted under review 2021.

25. Haque, M.A.; Chen, B. Research progresses on magnesium phosphate cement: A review. Constr. Build. Mater. 2019, 211, 885-898. [CrossRef]

26. Yang, N.; Shi, C.; Yang, J.; Chang, Y. Research Progresses in Magnesium Phosphate Cement-Based Materials. J. Mater. Civ. Eng. 2014, 26, 04014071. [CrossRef]

27. Bienvenido-Huertas, D.; Oliveira, M.; Rubio-Bellido, C.; Marín, D. A Comparative Analysis of the International Regulation of Thermal Properties in Building Envelope. Sustainability 2019, 11, 5574. [CrossRef]

28. Fernandes, M.S.; Rodrigues, E.; Gaspar, A.R.; Costa, J.; Álvaro, G. The impact of thermal transmittance variation on building design in the Mediterranean region. Appl. Energy 2019, 239, 581-597. [CrossRef] 
29. Directive 2010/31/EU of the European Parliament and of the Council of 19 May 2010 on the Energy Performance of Buildings. Available online: https:/ / eur-lex.europa.eu/legal-content/EN/TXT/?uri=celex:32010L0031 (accessed on 6 July 2021).

30. SIMPLIFY3D. Available online: www.simplify3d.com/support/print-quality-troubleshooting (accessed on 5 July 2021).

31. Baghban, M.H. Thermal insulating cementitious composite containing aerogel and phosphate-based binder. IOP Conf. Ser. Mater. Sci. Eng. 2019, 609, 062024. [CrossRef]

32. Falliano, D.; De Domenico, D.; Ricciardi, G.; Gugliandolo, E. 3D-printable lightweight foamed concrete and comparison with classical foamed concrete in terms of fresh state properties and mechanical strength. Constr. Build. Mater. 2020, 254, 119271. [CrossRef]

33. Rahul, A.V.; Santhanam, M. Evaluating the printability of concretes containing lightweight coarse aggregates. Cem. Concr. Compos. 2020, 109, 103570. [CrossRef]

34. Kaszynka, M.; Olczyk, N.; Techman, M.; Skibicki, S.; Zielinski, A.; Filipowicz, K.; Wroblewski, T.; Hoffmann, M. ThermalHumidity Parameters of 3D Printed Wall. IOP Conf. Ser. Mater. Sci. Eng. 2019, 471, 082018. [CrossRef]

35. Lim, S.; Buswell, R.A.; Le, T.T.; Austin, S.A.; Gibb, A.G.F.; Thorpe, T. Developments in construction-scale additive manufacturing processes. Autom. Constr. 2012, 21, 262-268. [CrossRef]

36. Pessoa, S.; Guimarães, A.S.; Lucas, S.S.; Simões, N. 3D printing in the construction industry-A systematic review of the thermal performance in buildings. Renew. Sustain. Energy Rev. 2021, 141, 110794. [CrossRef]

37. Khoshnevis, B.; Hwang, D.; Yao, K.-T.; Yeh, Z. Mega-scale fabrication by contour crafting. Int. J. Ind. Syst. Eng. 2006, 1, 301-320. [CrossRef] 